\title{
品質管理を考えた制御系の設計法
}

\author{
室津義定・大場史憲・西山建志 \\ 大阪府立大学工学部 堺市百舌鳥梅町 4 丁 \\ （昭和 46 年 1 月 6 日 受付)
}

\section{Design of Control Systems Considering Quality Control}

\author{
Yoshisada Murotsu, Fuminori Ohba and Tateshi Nishiyama \\ (College of Engineering, University of Osaka Prefecture, Sakai)
}

(Received January 6, 1971)

This paper is concerned with a design of control systems when the specifications of the systems' elements are subjected to random variations from their nominal values. We discuss how far the variations in the characteristics of the elements affect the performance of the overall system, and conversely how accurate each element should be in order that the performance of the overall system may be in the specified allowance. A design of an instrument servo system is presented to illustrate the proposed procedure.

\section{1. ま えがき}

制御系を短期間に効果的に設計・製作するためには, 系の構成に使用する部品の特性の定格值からのぼらつ きを考虑しなくてはならない. 特に, 大量生産によっ て部品を製造する場合，製品としての信頼性を高める ために各部品をいかに品質管理すれば良いかという問 題が生じる. このような問題に対して, 系を設計する 段階で考慮すべきことは，系の構成に使用する各部品 の特性を表わす定数の定格值からのばらつきが系全体 の性能にいかなる影響を与えるか，また逆に，系全体 の動作特性が指定された公差内にあるためには, 個々 の部品に要求される製品誤差の範囲はいかにあるべき かといらことである. このような問題に対する従来の 研究としては Chubb の著書 ${ }^{1)} 2,3$ の方法が述べ てある程度のように思われる，そこでこの論文では， このよらな問題に対するより簡単で直接的な 1 つのア プローチを与える，その基礎となる概念は，古典的制 御理論に打いて, 制御系の過渡応答はとの系の極抏よ び零点によって特性づけられるといらことである.す なわち，各部品の定数がその定格值からばらつくとき， 系全体の極和よび零点がいかなる影響を受けるかを考 察する. また計器サーボ系の例によってその関係を用 いて所望の精度を持つ系を構成するための部品の精度 を決定する手法を与える.

\section{2. 問 題 の 記 述}

与えられた問題は，1）各要素のばらつきが与えら れたとき，系全体の特性はどれだけばらつくか (Ana1ysis)，2） 各要素の精度をどれだけあげれば，系全 体の特性が所定の要求を満足しうるか (Synthesis), といらことであるが，これを前節で述べたように制御 系の極执よび零点の変動の問題に拈きかえて，以下の ように問題を設定することができる.

Fig. 1 に示した線形フィードバック系を考える.

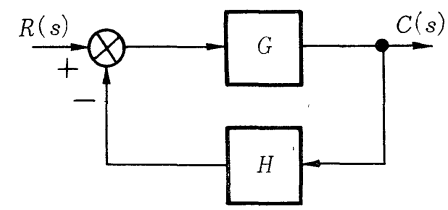

Fig. 1 Block diagram of a linear feedback control system

このとき入出力の関係式は周知のごとく次のようにな る.

$$
\frac{C(s)}{R(s)} \triangleq G_{c}=\frac{G}{1+G H}
$$

一般に $G_{c}$ の分母, 分子は, ラプラス演算子 $s$ の多 項式で表わして，次の形に書くことができる.

$$
G_{c}=K \frac{s^{m}+b_{m-1} s^{m-1}+\cdots+b_{1} s+b_{0}}{s^{n}+a_{n-1} s^{n-1}+\cdots+a_{1} s+a_{0}}(n \geqq m)
$$


ここに, $G_{c}$ の係数 $a_{i}(i=0, \cdots, n-1), b_{j}(j=0, \cdots$, $m-1)$ は，系を構成している部品の定数值によって きまるものである. したがって，部品の定数值を $K_{k}$ $(k=1,2, \cdots, q)$ で表わすと， $a_{i}$ 执よび $b_{j}$ は次のよ うにかける。

$$
\left.\begin{array}{l}
a_{i}=a_{i}\left(K_{1}, K_{2}, \cdots, K_{q}\right) \quad(i=0, \cdots, n-1) \\
b_{j}=b_{j}\left(K_{1}, K_{2}, \cdots, K_{q}\right) \quad(j=0, \cdots, m-1)
\end{array}\right\}
$$

しかしながら，実際には各部品は製作誤差や，特性を 測定によって決定する場合には測定誤差をともならの で，その定数值は定格值ど沶りの場合はほとんどなく， 定格值まわりにあるばらつきを持ったものと又なさな

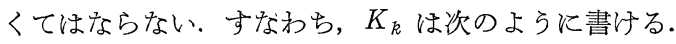

$$
K_{k}=K_{k}^{*}+\delta K_{k} \quad(k=1, \cdots, q)
$$

ここに, $K_{k}{ }^{*}$ は $K_{k}$ の定格値, $\delta K_{k}$ は $K_{k}{ }^{*}$ からの変 動分である。

このようにして, 部品の定数が定格值から变動する とき, $G_{c}$ の係数 $a_{i}$ 特よび $b_{j}$ は変動して次のようと 書ける.

$$
\left.\begin{array}{l}
a_{i}=a_{i}^{*}+\delta a_{i}=a_{i}+\sum_{k=1}^{q} \frac{\partial a_{i}}{\partial K_{k}} \delta K_{k}+O\left(\delta K_{k}\right) \\
b_{j}=b_{j}^{*}+\delta b_{j}=b_{j}^{*}+\sum_{k=1}^{q} \frac{\partial b_{j}}{\partial b_{k}} \delta K_{k}+O\left(\delta K_{k}\right)
\end{array}\right\}
$$

ここに, $a_{i}{ }^{*}=a_{i}\left(K_{1}{ }^{*}, K_{2}{ }^{*}, K_{q}{ }^{*}\right), b_{j}{ }^{*}=b_{j}\left(K_{1}{ }^{*}, K_{2}{ }^{*}, \cdots\right.$, $\left.K_{q}^{*}\right)$ であり, 偏導関数は, 定格值 $K_{k}=K_{k}^{*}(k=1$, ‥,q）飞怙汀る值とする。

以上の上うにして， $G_{c}$ の係数 $a_{i}, b_{j}$ の变動が求ま るので, 結局, $a_{i}, b_{j}$ の変動飞詨して, 制御系の特 性を支配する極叔よび零点がどのように変動するかを 考觉ればよい，したがって次のように問題を設定する ことができる.

【問題】 $\Gamma G_{c}$ の係数 $a_{i}, b_{j}(i=0, \cdots, n-1, j=0$, $\cdots, m-1)$ の平均值 $a_{i}^{*}, b_{j}^{*}$, 標準偏差 $\sigma_{a_{i}}, \sigma_{b_{j}}$ 拈よ び相関係数 $\rho_{a_{i} a_{j}}, \rho_{b_{i} b_{j}}$ がそれぞれ与兄られたとき， 極和よび零点の分散を計算せよ」.

\section{3. 極および零点の分散の計算法}

極执よび零点の分散の計算法は, 高次代数方程式の 係数の変動に対する根の分散の計算法にほかならない ので, 次の $n$ 次代数方程式について考完よう.

$$
s^{n}+a_{n-1} s^{n-1}+\cdots+a_{1} s+a_{0}=0
$$

いま，(5)式に招いて2 次以上の微小項を無視する 之, 各部品の定数の定格值 $K_{k}{ }^{*}$, 標準偏差 $\sigma_{K_{k}}$, 相関 係数 $\rho_{K_{k} K_{l}}(k, l=1, \cdots, q)$ が与兄られたとき, $a_{i}(i=$ $0, \cdots, n-1)$ の平均值は $a_{i}$ * で与兄られ, 分散抒よび 共分散は次のようとなる。

$$
\sigma_{a_{i}}{ }^{2} \triangleq\left[\left(\delta a_{i}\right)^{2}\right]^{*}=\sum_{k, l=1}^{q} \frac{\partial a_{i}}{\partial K_{k}} \cdot \frac{\partial a_{i}}{\partial K_{l}} \cdot \rho_{K_{k} K_{l}} \cdot \sigma_{K_{k}} \cdot \sigma_{K l}
$$

$$
\begin{aligned}
& \rho_{a_{i} a_{j} \cdot} \cdot \sigma_{a_{i}} \cdot \sigma_{a_{j}} \triangleq\left[\left(\delta a_{i} \cdot \delta a_{j}\right)\right]^{*} \\
& \quad=\sum_{k, l=1}^{q} \frac{\partial a_{\imath}}{\partial K_{k}} \cdot \frac{\partial a_{j}}{\partial K_{l}} \cdot \rho_{K_{k} K_{l}} \cdot \sigma_{K_{k}} \cdot \sigma_{K l}
\end{aligned}
$$

ただし， $[\cdot]^{*}$ は（·）の期待值を表わす。したがって， （6)式に损いて，係数 $a_{i}$ の統計的性質を次のように 仮定する.

(I ) $a_{i}(i=0,1, \cdots, n-1)$ の平均值 $a_{i}^{*}$, 標準偏差 $\sigma_{a_{i}}$, 拈よび, 相関係数 $\rho_{a_{i} a_{j}}(i, j=0,1, \cdots, n-1)$ が与 えられている.

（II） $a_{i}$ の平均值からのばらつきはあまり大きく なく，2次以上の項は無視できる.

いま，(6) 式の係数 $a_{i}=a_{i} *(i=0,1, \cdots, n-1)$ に 対する根を $P_{j}^{*}(j=1,2, \cdots, n)$ とする。すなわち，

$\left(P_{j}^{*}\right)^{n}+a_{n-1} *\left(P_{j}\right)^{n-1}+\cdots+a_{1} * P_{j} *+a_{0} *=0$

$$
(j=1,2, \cdots, n)
$$

各係数が変動して,

$$
a_{i}=a_{i}{ }^{*}+\delta a_{i} \quad(i=0,1, \cdots, n-1)
$$

となったときの（6）式の根を,

$$
P_{j}=P_{j} *+\delta P_{j} \quad(j=1,2, \cdots, n)
$$

そする。すすなわち、

$$
\begin{aligned}
& \left(P_{j}^{*}+\delta P_{j}\right)^{n}+\left(a_{n-1} *+\delta a_{n-1}\right)\left(P_{j}^{*}+\delta P_{j}\right)^{n-1}+\cdots \\
& \quad+\left(a_{1}{ }^{*}+\delta a_{1}\right)\left(P_{j}^{*}+\delta P_{j}\right)+\left(a_{0}{ }^{*}+\delta a_{0}\right)=0
\end{aligned}
$$

(12) 式を展開して，2 次以上の項を無視して， $\delta P_{j}$ 汇関して解くと,

$$
\delta P_{j}=\frac{\sum_{k=0}^{n-1}\left(P_{j^{*}}\right)^{k} \cdot \delta a_{k}}{D_{j}} \quad(j=1,2, \cdots, n) \quad(13)^{* 1}
$$

となる.ただし， $D_{j}=\sum_{k=0}^{n-1}(k+1)\left(P^{*}\right)^{k} a_{k+1} *, a_{n}^{*}=1$

したがって， $P_{j}^{*}$ が実根である場合には，根の分散 は次のようになる.

$$
\sigma_{P_{j}}{ }^{2} \triangleq\left[\left(\delta P_{j}\right)^{2}\right]^{*}=\frac{1}{D^{2}} \sum_{k, l=0}^{n-1}\left(P_{j}^{*}\right)^{k+l} \rho_{a_{k} a_{l}} \cdot \sigma_{a_{k}} \cdot \sigma_{a l}
$$

*1 (13) 式は $D_{j} \neq 0$ を仮定している. $D_{j}=0$ の場合は,

（12）式を展開して 2 次の項までを採用し， $A_{j} \cdot \delta P_{j}{ }^{2}+B_{j} \cdot \delta P_{j}+C_{j}=0$ ただし，

$$
\begin{aligned}
A_{j} & =\sum_{k=0}^{n-2} \frac{(k+2)(k+1)}{2 !}\left(P_{j}^{*}\right)^{k} a_{k+2}{ }^{*} \\
B_{j} & =\sum_{k=0}^{n-2}(k+1)\left(P_{j}^{*}\right)^{k} \delta a_{k+1} \\
C_{j} & =\sum_{k=0}^{n-1}\left(P_{j}^{*}\right)^{k} \delta a_{k}
\end{aligned}
$$

なる 2 次式の根として $\delta P_{j}$ が得られるので計算は非常 に複雑になる. しかし, $D_{j}=0$ の場合は, 特性方程式 （6）が重根を持つ場合に相当するので，このような点 を設計点として選ぶことは少ない。 
次に， $P_{j}^{*}$ が複素根の場合を考劣よう．このとき， まず（13）式を実数部 ( Re と略す) と虚数部 (Im と 略す）に分沪て書くと，

$$
\delta P_{j}=\sum_{k=0}^{n-1} R_{k} \delta a_{k}+i \sum_{k=0}^{n-1} I_{k} \delta a_{k}
$$

となる，ただし，

$$
R_{k}=\operatorname{Re}\left[\frac{\left(P_{j}^{*}\right)^{k}}{D_{j}}\right], I_{k}=\operatorname{Im}\left[\frac{\left(P_{j}^{*}\right)^{k}}{D_{j}}\right]
$$

である、したがって， $\delta P_{j}$ の実数部と虚数部の分散括 よび共分散は，次のように計算される.

$$
\left.\begin{array}{l}
{\left[\left\{\operatorname{Re}\left(\delta P_{j}\right)\right\}^{2}\right]^{*}=\sum_{k, l=0}^{n-1} R_{k} \cdot R_{l} \cdot \rho_{a_{k} a_{l}} \cdot \sigma_{a_{k}} \cdot \sigma_{a_{l}}} \\
{\left[\left\{\operatorname{Im}\left(\delta P_{j}\right)\right\}^{2}\right]^{*}=\sum_{k, l=0}^{n-1} I_{k} \cdot I_{l} \cdot \rho_{a_{k} a_{l}} \cdot \sigma_{a_{k}} \cdot \sigma_{a_{l}}} \\
{\left[\operatorname{Re}\left(\delta P_{j}\right) \cdot \operatorname{Im}\left(\delta P_{j}\right)\right]^{*}=\sum_{k, l=0}^{n-1} R_{k} \cdot I_{l} \cdot \rho_{a_{k} a_{l}} \cdot \sigma_{a_{k}} \cdot \sigma_{a_{l}}}
\end{array}\right\}
$$

いっぽう，複素根 $P_{j}$ の振幅特よび位相角は，

$$
\left.\begin{array}{l}
\left|P_{j}\right|=\sqrt{\left\{\operatorname{Re}\left(P_{j}\right)\right\}^{2}+\left\{\operatorname{Im}\left(P_{j}\right)\right\}^{2}} \\
\angle P_{j}=\tan ^{-1} \frac{\operatorname{Im}\left(P_{j}\right)}{\operatorname{Re}\left(P_{j}\right)}
\end{array}\right\}
$$

で与えられるので，これらの分散は次のように計算さ れる2).

$$
\begin{aligned}
& \sigma_{\left|P_{j}\right|^{2}}=\frac{\left\{\operatorname{Re}\left(P_{j}^{*}\right)\right\}^{2}}{\left|P_{j}\right|^{2}}\left[\left\{\operatorname{Re}\left(\delta P_{j}\right)\right\}^{2}\right]^{*} \\
& +\frac{\left\{\operatorname{Im}\left(P_{j}^{*}\right)\right\}^{2}}{\left|P_{j}\right|^{2}}\left[\left\{\operatorname{Im}\left(\delta P_{j}\right)\right\}^{2}\right]^{*} \\
& +\frac{2 \operatorname{Re}\left(P_{j}^{*}\right) \cdot \operatorname{Im}\left(P_{j}^{*}\right)}{\left|P_{j}^{*}\right|^{2}}\left[\operatorname{Re}\left(\delta P_{j}\right) \cdot \operatorname{Im}\left(\delta P_{j}\right)\right]^{*} \\
& \sigma_{\angle P_{j}}{ }^{2}=\frac{\left\{\operatorname{Im}\left(P_{j}^{*}\right)\right\}^{2}}{\left|P_{j}\right|^{4}}\left[\left\{\operatorname{Re}\left(\delta P_{j}\right)\right\}^{2}\right]^{*} \\
& +\frac{\left.\left\{\operatorname{Re}\left(P_{j}\right)^{*}\right)\right\}^{2}}{\left|P_{j}^{*}\right|^{4}}\left[\left\{\operatorname{Im}\left(\delta P_{j}\right)\right\}^{2}\right]^{*} \\
& \quad-\frac{2 \operatorname{Re}\left(P_{j}^{*}\right) \cdot \operatorname{Im}\left(P_{j}^{*}\right)}{\left|P_{j}^{*}\right|^{4}}\left[\operatorname{Re}\left(\delta P_{j}\right) \cdot \operatorname{Im}\left(\delta P_{j}\right)\right]^{*}
\end{aligned}
$$

\section{4. 計器サーボ系に対する設計仕様}

2. で提起した問題を Fig. 2 に示すよらな計器サー ボ系1について考えよう.

この系の閉ループ伝達関数は次式で与えられる.

$$
\frac{C(s)}{R(s)}=\frac{K}{s^{4}+a_{3} s^{3}+a_{2} s^{2}+a_{1} s+a_{0}}
$$
ただし，

$$
\begin{aligned}
& K=a_{0}=\frac{K_{s} \cdot K_{f} \cdot K_{a} \cdot K_{m} \cdot \cos \left(\phi_{f}+\phi_{a}\right)}{N \cdot J_{m} \cdot J_{L}} \\
& a_{1}=\frac{K_{s} \cdot B_{m}+K_{s} \cdot K_{g} \cdot K_{a} \cdot K_{m} \cdot \cos \left(\phi_{g}+\phi_{a}\right)}{J_{m} \cdot J_{L}}
\end{aligned}
$$

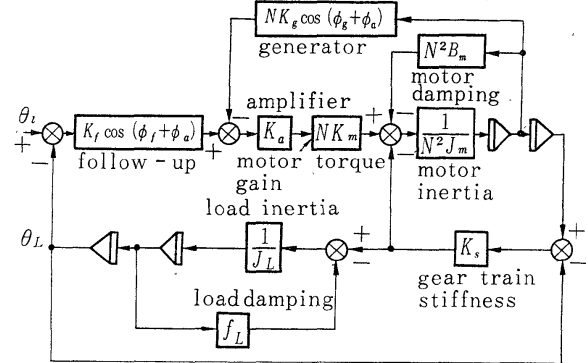

Fig. 2 Block diagram of a typical instrument servo system

$$
\begin{aligned}
& +\frac{K_{s} \cdot f_{L}}{N^{2} \cdot J_{m} \cdot J_{L}} \cdot \\
a_{2}= & \frac{B_{m} \cdot f_{L}+K_{a} \cdot K_{g} \cdot K_{m} \cdot f_{L} \cdot \cos \left(\phi_{g}+\phi_{a}\right)}{J_{m} \cdot J_{L}} \\
& +\frac{K_{s}}{J_{L}}+\frac{K_{s}}{N^{2} \cdot J_{m}} \\
a_{3}= & \frac{B_{m}+K_{g} \cdot K_{a} \cdot K_{m} \cdot \cos \left(\phi_{g}+\phi_{a}\right)}{J_{m}}+\frac{f_{L}}{J_{L}}
\end{aligned}
$$

である。

このような計器サーボ系に执いては, 従来, 卓越根 に注目して，減衰比 $\zeta$ の值が $0.6 \sim 0.8$ になるよらに 設計されることが望をしいとされている3)。 これを位 相角で表わすと Fig. 3 のようになる。しかしながら，

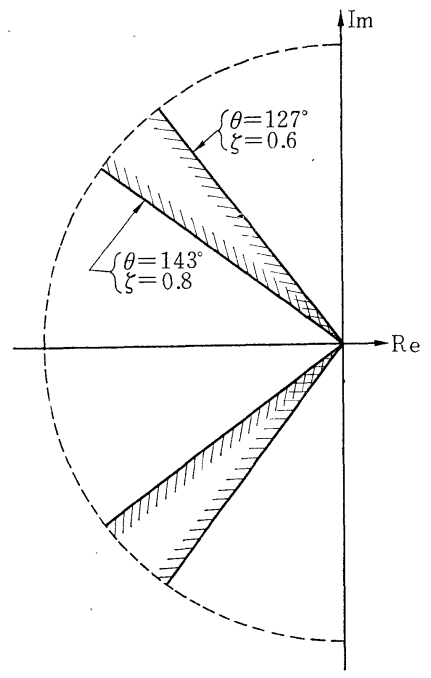

Fig. 3 Desirable region of characteristic poles in $s$-plane

このように設計された系を構成する各部品の定数の值 は，製作誤差や測定誤差のために，定格値のまわりに あるばらつきをもっているものとみなさなければなら ない，そこで，2.に提起したよらな，系の特性のば らつきについての Analysis の問題と Synthesis の 問題が生ずる.したがって，1つの設計仕様としては, 
たとえば「P\% の確率で $\zeta=0.6 〜 0.8$ となるように せよ」といら形で与壳られる。

以下に，3. の手法を用いて，このような問題に対 する 1 つのアプローチを与える．簡単のためにまず (21) 式を 2 次系で近似して取り扱い，その後 (21)

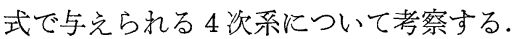

\section{5. 計器サーボ系の統計的設計法}

\section{$5 \cdot 12$ 次系で近似した場合}

（21）式に永いて，負荷減衰力が非常に小さくて， 歯車列岡性がきわめて大きい場合は， $f_{L} \doteqdot 0, K_{S} \rightarrow \infty$ で近似できるので，次のよらな 2 次系で与えられるこ とになる。

$$
\frac{c(s)}{R(s)}=\frac{K}{s^{2}+a_{1} s+a_{0}}
$$

ただし

$$
\begin{aligned}
& K=a_{0}=\frac{K_{f} \cdot K_{a} \cdot N \cdot K_{m} \cdot \cos \left(\phi_{f}+\phi_{a}\right)}{N^{2} \cdot J_{m}+J_{L}} \\
& a_{1}=\frac{K_{a} \cdot N^{2} \cdot K_{m} \cdot K_{g} \cdot \cos \left(\phi_{g}+\phi_{a}\right)+N^{2} \cdot B_{m}}{N^{2} J_{m}+J_{L}}
\end{aligned}
$$

である。

(22) 式に扮いて, 特性方程式の係数 $a_{i}(i=0,1)$ の 分散扣よび共分散は，（7)，（8）式から，各部品の 定数の分散によって次のように与えられる.

$$
\begin{aligned}
& \sigma_{a_{1}}{ }^{2}=\left(\frac{\partial a_{1}}{\partial K_{a}} K_{a}\right)^{* 2} \sigma_{x K_{a}}{ }^{2}+\left(\frac{\partial a_{1}}{\partial K_{m}} K_{m}\right)^{* 2} \sigma_{x K_{m}}{ }^{2} \\
& +\left(\frac{\partial a_{1}}{\partial J_{m}} J_{m}\right)^{* 2} \sigma x J_{m}{ }^{2}+\left(\frac{\partial a_{1}}{\partial B_{m}} B_{m}\right)^{* 2} \sigma x_{B_{m}}{ }^{2} \\
& +\left(\frac{\partial a_{1}}{\partial K_{g}} K_{g}\right)^{* 2} \sigma_{x_{K g}}{ }^{2}+\left(\frac{\partial a_{1}}{\partial J_{L}} J_{L}\right)^{* 2} \sigma x_{J_{L}}{ }^{2} \\
& \sigma_{a_{0}}{ }^{2}=\left(\frac{\partial a_{0}}{\partial K_{f}} K_{f}\right)^{* 2} \sigma x_{K_{f}}{ }^{2}+\left(\frac{\partial a_{0}}{\partial K_{a}} K_{a}\right)^{* 2} \sigma x_{K_{a}}{ }^{2} \\
& +\left(\frac{\partial a_{0}}{\partial K_{m}} K_{m}\right)^{* 2} \sigma x_{K_{m}}{ }^{2}+\left(\frac{\partial a_{0}}{\partial J_{m}} j_{m}\right)^{* 2} \sigma x_{J_{m}}{ }^{2} \\
& +\left(\frac{\partial \dot{a}_{0}}{\partial J_{L}} J_{L}\right)^{* 2} \sigma x J_{L}^{2} \\
& \rho_{a_{1} a_{0}} \cdot \sigma_{a_{1}} \cdot \sigma_{a_{0}}=\left(\frac{\partial a_{1}}{\partial K_{a}} K_{a}\right)^{*}\left(\frac{\partial a_{0}}{\partial K_{a}} K_{a}\right)^{*} \sigma x_{K_{a}}{ }^{2} \\
& +\left(\frac{\partial a_{1}}{\partial K_{m}} K_{m}\right)^{*}\left(\frac{\partial a_{0}}{\partial K_{m}} K_{m}\right)^{*} \sigma x_{K_{m}}{ }^{2} \\
& +\left(\frac{\partial a_{1}}{\partial J_{m}} J_{m}\right)^{*}\left(\frac{\partial a_{0}}{\partial J_{m}} J_{m}\right)^{*} \sigma x_{J_{m}}^{2} \\
& +\left(\frac{\partial a_{1}}{\partial J_{L}} J_{L}\right)^{*}\left(\frac{\partial a_{0}}{\partial J_{L}} J_{L}\right)^{*} \sigma_{x J_{L}}{ }^{2}
\end{aligned}
$$

上式に括いて, $x(\cdot)=\delta(\cdot) /(\cdot)$ *特いた. たとえば， $x_{K_{a}}$ は $\delta K_{a} / K_{a} *$ であり, $K_{\alpha}$ に拉将る変動の, 定格, 值に対する割合を与える，したがって $\sigma x_{K_{a}}$ は，定格 值に対するばらつきの割合を与えている，また，各部
品の定数は統計的に独立であるとした。

いま，構成要素の定数が定格值であるとき，すなわ ち, $a_{i}(i=0,1)$ が $a_{i}^{*}(i=0,1)$ のときの特性根が次 のよらな複素根であるとする。

$$
P_{1,2} *=-R^{*}+i I^{*}
$$

このとき, 定格值から, 要素の定数が変動すると特性 根の変動は,

$$
\delta P_{1}=\frac{\delta a_{1}}{2}+i \frac{R^{*} \delta a_{1}-\delta a_{0}}{2 I^{*}}
$$

となる。なた，(17）式から特性根の実数部および虚 数部の分散执よび共分散は,

$$
\begin{aligned}
& {\left[\left\{\operatorname{Re}\left(\delta P_{1}\right)\right\}^{2}\right]^{*}=\frac{1}{4}\left[\left(\delta a_{1}\right)^{2}\right]^{*}} \\
& {\left[\left\{\operatorname{Im}\left(\delta P_{1}\right)\right\}^{2}\right]^{*}=\frac{1}{4 \cdot\left(I^{*}\right)^{2}}\left[\left(R^{*}\right)^{2}\left\{\left(\delta a_{1}\right)^{2}\right\}^{*}\right.} \\
& \left.\quad+\left\{\left(\delta a_{0}\right)^{2}\right\}^{*}-2 R^{*}\left(\delta a_{1} \cdot \delta a_{0}\right)^{*}\right] \\
& {\left[\operatorname{Re}\left(\delta P_{1}\right) \cdot \operatorname{Im}\left(\delta P_{1}\right)\right]^{*}=\frac{1}{4 I^{*}}\left[R^{*}\left\{\delta a_{1}\right)^{2}\right\}^{*}} \\
& \left.\quad-\left(\delta a_{1} \cdot \delta a_{0}\right)^{*}\right]
\end{aligned}
$$

となる.このとき, 特性根の振幅预よび位相角の分散 は（19）（20）式から次のように与光られる.

$$
\begin{aligned}
& \sigma_{\left|P_{1}\right|^{2}}=\frac{1}{4\left|P_{1}^{*}\right|^{2}} \sigma_{a_{0}} \\
& \sigma_{\angle P_{1}}{ }^{2}=\frac{1}{4\left|P_{1}^{*}\right|^{4}}\left[\left\{I^{*}+\frac{\left(R^{*}\right)^{2}}{I^{*}}\right\} \sigma_{a_{1}}{ }^{2}\right. \\
& +\left(\frac{R^{*}}{I^{*}}\right)^{2} \sigma_{a_{0}}{ }^{2}-2\left\{I^{*}+\frac{\left(R^{*}\right)^{2}}{I^{*}}\right\} \frac{R^{*}}{I^{*}} \rho_{a_{1} a_{0}} \cdot \sigma_{a_{1}} \cdot \sigma_{a_{0}}
\end{aligned}
$$

このようにして特性根の分散が求まると，4.にの ベたような，たとえば減衰比らについての設計仕様を みたす設計が可能となる，以下其体的にデータを与光 てその手法を考察する。

いま，各部品の定数の定格值および標準偏差が次の よらに与光られているものとする。

$K_{f} *=2.441[\mathrm{~V} / \mathrm{rad}], \sigma x_{K f}=0.2, K_{g} *=3.290 \cdot 10^{-4}$ $[\mathrm{V} / \mathrm{rad} / \mathrm{s}], \quad \sigma_{x_{K g}}=0.1, K_{a}{ }^{*}=1.980 \cdot 10^{3}[\mathrm{~V} / \mathrm{V}]$, $\sigma x_{K_{a}}=0.2, \quad K_{m} *=2.145 \cdot 10^{-3}[\mathrm{oz}-\mathrm{in} / \mathrm{V}], \quad \sigma x_{K_{m}}=$ $0.2, B_{m} *=2.125 \cdot 10^{-4}[\mathrm{oz}-\mathrm{in} / \mathrm{rad} / \mathrm{s}], \quad \sigma x_{B_{m}}=0.3$, $J_{m}{ }^{*}=1.107 \cdot 10^{-5}\left[\mathrm{oz}-\mathrm{in} / \mathrm{rad} / \mathrm{s}^{2}\right], \quad \sigma x_{J m}=0.1, J_{L} *=$ $1.334 \cdot 10^{-2}\left[\mathrm{oz}-\mathrm{in} / \mathrm{rad} / \mathrm{s}^{2}\right], \quad \sigma x_{J L}=0.1, \quad N=95.92$, $\phi_{f} *=\phi_{g}{ }^{*}=\phi_{a}{ }^{*}=0$.

このとき，定格值に対する特性根は次のようになる。 $P_{1,2}{ }^{*}=-64.29 \pm 67.08 i$

またそのときの位相角执よび減衰比は，

$\theta^{*}= \pm 133.78[\mathrm{deg}], \quad \zeta^{*}=0.7220$

となる. 次に特性根の分散を計算すると,

$\left.\sigma_{\mid P 1}\right|^{2}=2.783 \cdot 10^{2}$ 
$\sigma \angle p_{1}^{2}=2.979 \cdot 10^{-2}\left[\mathrm{rad}^{2}\right]$

となる.ししたがって，位相角の標準偏差は，

$\sigma \angle p_{1}=9.887$ [deg]

となる. いっぽう, 減衰比 $\zeta=0.6 \sim 0.8$ 亿対応する 位相角は Fig. 3 に示したように $\theta=127 \sim 143 \mathrm{deg}$ で あるから，定格值に対する位相角の許容範囲は，

$133.78^{\circ}-6.78^{\circ} \leq \theta \leq 133.78^{\circ}+9.22^{\circ}$

である、したがって，位相角の分布*2がガウス分布で 西ると仮定したとき，この範囲からはみ出す確率は $\Phi(t)=\frac{1}{\sqrt{2 \pi}} e^{-t^{2} / 2}$ としたとき，

$$
\int_{-\infty}^{-6.78 / 9.887} \Phi(t) d t+\int_{9.22 / 9.887}^{\infty} \Phi(t) d t=0.4245
$$

である．結局，この系が設計仕様を満足する確率は， $57.55 \%$ 亿すぎないことがわかる。それでは，次に 95 \%の確率で設計仕様をみたすように，位相角が許容範 囲にはいるためには，各部品の精度をどれだけ上げれ ばよいかを調べる．このとき，位相角がその許容範围 からはみだす確率は $5 \%$ 以下でなければならないから， 許される位相角の標準偏差をのとすると，のは，

$$
\int_{-\infty}^{-6.78 / \sigma} \Phi(t) d t+\int_{9.22 / \sigma}^{\infty} \Phi(t) d t \leq 0.05
$$

をみたさなければならない，そこで， $\sigma=4.08 \mathrm{deg}$ と すると，この確率は 0.0497 となって与兄られた仕様 をみたすことがわかる。、いま，各部品の精度を一様に 高めるとして，位相角の標準偏差を $4.08 \mathrm{deg}$ 以下に するためには，各部品の精度を 9.887/4.08=2.42 倍 高めなげればならないことがわかる。

いっぽう， $P_{1,2}$ の分散を計算すると，

$$
\begin{aligned}
& \sigma_{\left|P_{1}\right|^{2}}=5.571 \times 10 \\
& \sigma \angle P_{1}=6.589 \times 10^{-2} \quad\left[\mathrm{rad}^{2}\right]
\end{aligned}
$$

となる. したがって，位相角の標準偏差は，

$$
\sigma \angle P_{1}=14.71 \quad[\mathrm{deg}]
$$

となる．以下，前と同様にして， $\theta=127 \sim 143^{\circ}$ には いる確率は $41.19 \%$ となることがわかる。また，95\% の確率でこの卓越根の位相角がこの範囲にはいるよう にするためには, 各部品の精度を一様に上げるとすれ ば， 3.61 倍倍高めなければならないことがわかる。

\section{6. 実際問題への適用についての注意}

前章においては, 設計法の説明を簡単にするために, 各部品の精度を一様に高めることによって, 制御系の 特性を許容範囲に入れることを考光た。しかし，実際 問題に括いては一般に, 調整個所が設けられているこ

*2 位相角の分布は前もってわからないので, 実際には，各 部品の定数の分布が与えられたとき，モンテカルロ法な どにより検証する必要がある(付録参照).
ともあろら乙，また感度的な立場からは，制御系のば らつきに最も強く影響する部品の精度を上げれば有利 であることがわかる，そこで本章では，これらの問題 について考察する. 簡単のために, 5. に述べた計器 サーボ系の場合について考觉る。

まず，各部品のばらつきが制御系の特性に及ぼす影 響の度合（感度）について考察する．個々の部品の感 度は，(23）式に扮いてその部品に対する分散にかか っている係数と，(27) 式の係数の大きさによって決 まる、したがって, 各部品の感度の割合は容易に計算 できる. いっぽう，(28）式から，許される位相角の 標準偏差 $\sigma$ が求まると, その值を(27) 式左辺に代入 することにより先に求めた各部品の感度の割合にした がってそれぞれの部品の精度をいか添ど上げれば良い かはただらに計算できる。

次に，調整個所が設けられている場合を考光よう。 このとき，そのパラメータを調整することによって完 全に系全体の特性が変兄られる場合には本論文の上う な精度の検討は必要でない。乙かし実際には, そのパ ラメータの可調整範囲は限られているので, 調整され らる位相角の範围は限定される。このときには, 本論 文の手法を用いることによって, 調整可能なパラメー タによっても調整できない場合はどのくらいの確率で 起こるかがわかるし，逆に，指定された確率で所望の 特性飞調整可能であるための部品の精度を決定するこ ともできる.ささらに, 部品の精度が指定されている場 合には, 調整可能なパラメータの可調整範囲を決定す ることもできる.

\section{7.むす、び}

この論文では, 生産現場に执いて特に大切な品質管 理の問題に関連して, 制御系の設計, 製作にあたって 製品としての信頼性を高めるために系の構成に使用す る部品の特性のばらつきを考虑した設計法を与えた。 ここに与光た設計法を用いることによって不必要涪 品の精度を要求することなく, 所望の精度を有する系 を構成することが可能となり, 経済的な無駄をなくす ることができる、な特，この論文では，制御系の特性 が極点と零点で記述される場合について取扱った。 し かしながら, 定常特性, 周波数特性あるいは最適制御 理論のように評価関数によって制御系の特性の記述が なされる場合に対しても，この論文の考光方を拡張す ることができる.

末筆ながら，この研究に対して有益な御討論をいた だいた大阪府立大学工学部津村俊弘助教授拈よび神戸 大学工学部岩壼卓三助教授に心より感謝する. 
参考文 献

1) Chubb 著, 金沢訳 : 計器サーボ系の 設計法, 学献社 (1969)
2）岩壼・室津・渡辺：ロータのつりあわせに及ぼす測定 詥差の影響, 日本 機械 学会 講演論文集 No. 700-17 (1970-10)

3）伊沢：自動制御入門，オーム社， p.176（昭 40）

\section{付}

録

5. に与六た例題では，各部品の定数がガウス分布 れわれわれの提案した近似法は安全側の設計法を与 をしているとき，特性根の位相角の分布はガウス分布 えていることがわかる

であると仮定した。 ここでは，モンテカルロ法に よって位相角の分布を調べる，計算機を使って， 3000 回の乱数発生によって 得た位相角の分布を Fig. 4 亿示す.これを $\chi^{2}$ テストすると， 42 自 由度に対する $\chi^{2}$ 值が 608 となり，この分布は ガウス分布とみなせないことがわかる。しかし， 平均值からの偏差の小さい所ではガウス分布と良 く一致している。また，このようにして得た，平 均值抢よび標準偏差は $\theta_{m}{ }^{*}=134.8^{\circ}$ おっよび， $\sigma_{\theta_{m}}$ $=11.8^{\circ}$ であるのに対して, われわ机の近似計算 では, 平均值 $\theta^{*}=133.78^{\circ}$, 標準偏差 $\sigma_{\theta}=14.71^{\circ}$ といら結果を得ている。 このようにして，実際の 位相角の分布は, ガウス分布のように, 平均值か らきわめて大きな偏差は和こらないことが予想さ

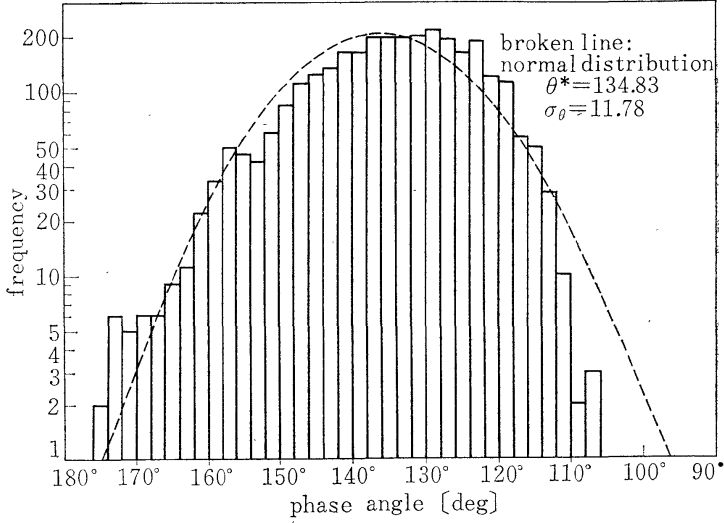

Fig. 4 Frequency histogram of phase angle 